\title{
Optoacoustic gas-analysis for diagnostics of biosystems
}

\author{
Boris G. Ageev, Olga Y. Nikiforova, Yurii N. Ponomarev*, and Valeria A. Sapozhnikova \\ V. E. Zuev Institute of Atmospheric Optics SB RAS, Tomsk 634055, Russia \\ *e-mail:yupon@iao.ru
}

\begin{abstract}
A possibility of detecting biogenic gases by the laser optoacoustic gas-analysis method is shown. The construction and specifications of instruments, developed for this purpose, are described. Examples of the analysis of gas samples of various biological objects, like air, expired by patients, suffered from different illnesses, and residual gases in the wood of year rings of conifers are given together with recommendations on applying the received information. (C) 2019 Journal of Biomedical Photonics \& Engineering.
\end{abstract}

Keywords: spectroscopy; absorption spectra; $\mathrm{CO}_{2}$ laser; carbon dioxide; tree rings; human breath.

Paper \#3311 received 24 Dec 2018; revised manuscript received 20 Mar 2019; accepted for publication 20 Mar 2019; published online 29 Mar 2019. doi: 10.18287/JBPE19.05.010304.

\section{Introduction}

Optoacoustic method (OA) refers to the group of calorimetric ones. A studying sample (gas, liquid, solid) is the detector of the absorbed power. The OA method is widely used in molecular spectroscopy and gas analysis with the use of different lasers, generating radiation in interval from UV to far IR range. It is characterized by the following properties [1-3]:

1. The OA signal is zero in the absence of the absorption in the sample.

2 . The signal-to-noise ratio increases proportionally to the radiation source power, up to the mode of the absorption saturation.

3. The OA signal depends linearly on the concentration of absorbing gas molecules at the concentration variation within 4-5 orders of magnitude.

4. The OA signal amplitude is the intensive parameter of the studied sample, i.e., it does not depend on its sizes. This circumstance allows us to work with gas cells of small volumes, easily controlling in them temperature, pressure, and gas composition.

In High-Resolution Spectroscopy the OA method is successfully used in smoothly wavelength-generating narrow-band lasers, particularly, in the diode ones [4-6]. In the diode-laser spectrometers the resonant OA detector in the form of differential Helmholtz resonator [4] is successfully used, providing for measurements of absorption cross-sections at vibrational-rotational molecular transitions of up to $4 \cdot 10^{-23} \mathrm{~cm}^{2} / \mathrm{mol}$.

A wide class of gas lasers, generating radiation at molecular transitions of active media, such as $\mathrm{CO}, \mathrm{CO}_{2}$,
$\mathrm{NH}_{3}$, are used in laser OA gas-analyzers for the ecological control of atmospheric contaminations, analysis of the expired air composition, aiming at the diagnostics of bronchopulmonary illnesses, diagnostics of vapors of dangerous chemical compounds, and in series of other applications [7-11].

In this paper, the application of the laser OA gasanalysis to detection of biogenic gases is demonstrated; the constructions and specifications of the used instruments are described; examples of the analysis of different biological samples are presented, such as air, expired by patients, suffering from different illnesses; residual gases in the wood of yearly rings of conifers; and recommendations are formulated on the use of the obtained information.

\section{Optoacoustic instrumentation for the analysis of biogenic gases}

\subsection{Description of the construction and specifications of the used instruments}

The analytical investigation of gaseous samples from biological objects in the framework of this work conducting was performed with two gas-analyzers: ILPA-1 and OAD-1. The instruments were assembled by one principal scheme (Fig. $1, a, b$ ) on the base of waveguide frequency-tunable $\mathrm{CO}_{2}$ lasers [12]. The lasers emit in bands of 10 and $9 \mu \mathrm{m}$ at more than 70 lines of $P$ and $R$ branches at an output generation power up to $3 \mathrm{~W}$ at strong lines and up to $0.5 \mathrm{~W}$ at weak ones. 


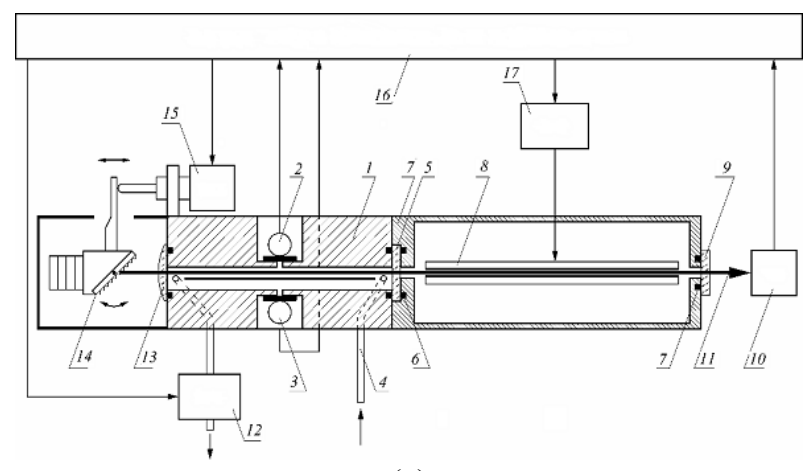

(a)

1 - optoacoustic detector, 2,3 - microphones, 4 - inputoutput of gas sample, 5 - passage window, 6 - thickening, 7 - body of the emitter of waveguide $\mathrm{CO}_{2}$ laser, 8 waveguide, 9 - output mirror of the laser, 10 - receiver of radiation, 11 - output radiation of the laser, 12 - air pump, 13 - adjusting lens, 14 - unit of retuning of radiation wavelength with diffraction grating, 15 - step actuator of the retuning unit, 16 - unit of control and indication, 17 HF generator of laser pumping.

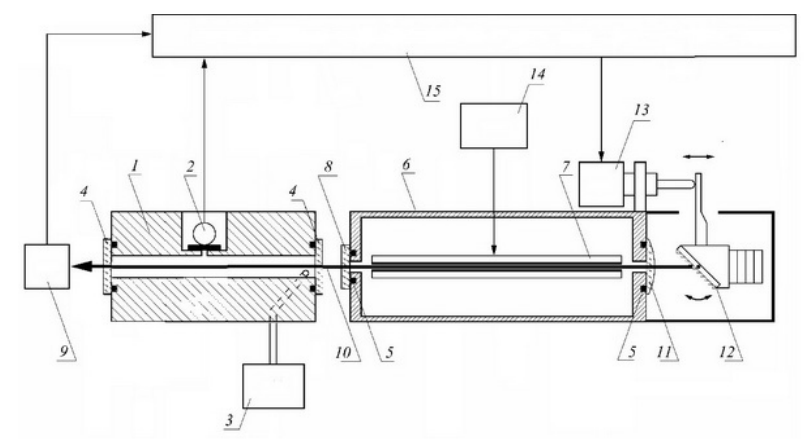

(b)

1 - optoacoustic detector, 2 - microphone, 3 - vacuum post, 4 - passage window, 5 - thickening, 6 - body of emitter of waveguide $\mathrm{CO}_{2}$ laser, 7 - waveguide, 8 - output mirror, 9 - receiver of radiation, 10 - output laser radiation, 11 - adjusting lens, 12 - unit of retuning of radiation wavelength with diffraction grating, 13 - step actuator of the retuning unit, $14-\mathrm{HF}$ generator of laser pumping, 15 - unit of control and indication.

Fig. 1 Schemes of laser optoacoustic gas-analyzers: ILPA1 (a) and OAD-1 (b).

Each device has its own constructive properties: the ILPA-1 is a transportable instrument, produced in small series (company "Special technologies" Ltd, Novosibirsk), and has an intra-resonator location of the detector [13]. In the instrument, the resonant differential OA flow-type detector is used, which allows pumping of the gas sample with the air pump through the detector. The gas-analyzer sizes are $91.5 \times 31.0 \times 16.0$ $\mathrm{cm}$, and its weight is no more than $27 \mathrm{~kg}$. The instrument exterior is shown in Fig. 2. The instrument OAD-1 (our proper elaboration) [10] is a stand variant of ILPA-1 one with the beyond-resonator detector of non-resonant type. The detector evacuation and filling in with a sample of the studying gas are performed with the help of the vacuum post. As well, there are differences in the element bases of the gasanalyzers, the most important of which are the modification of laser sources and the type of the used microphones.

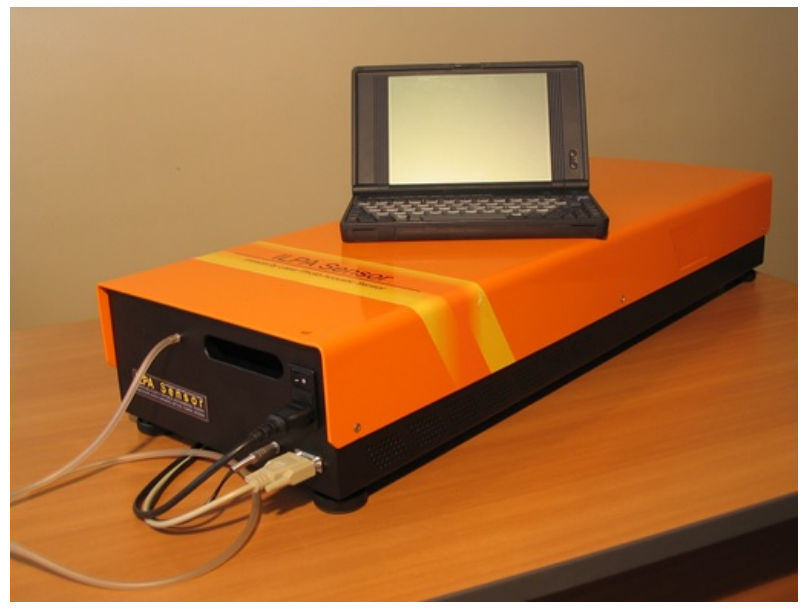

Fig. 2 General view of gas-analyzer ILPA-1.

The operation of the gas-analyzers is based on the $\mathrm{OA}$ effect, arising in the result of absorption of $\mathrm{CO}_{2}$ laser radiation by gases. The control for the radiation spectrum retuning is performed with the help of the personal computer through the control block with the use of the specially developed computer program ILPA Sensor. Laser radiation passes through the OA detector, which is a cylindrical cell with condenser microphones, build in the side wall. Gas molecules, having absorption lines at the $\mathrm{CO}_{2}$ laser wavelengths, absorb the modulated radiation of the laser. In this case, acoustic vibrations at the modulation frequency are formed inside the $\mathrm{OAD}$ and are recorded by microphones. The value of the measured acoustic signal, normalized to the magnitude of the laser radiation power, is proportional to the magnitude of the molecular absorption at the given concentration of the absorbing gas in the sample. Signals of the detector microphone mic and radiation receiver pyro are put first to wideband preamplifiers and then to the system of measuring and recording, based on sound cart of the personal computer. As the measurement result, a file appears with recorded values of mic, pyro, and absorption $=$ mic/pyro at corresponding generation lines, i.e., the analog of the sample absorption spectrum. The information on the recorded spectrum is displayed also on the monitor of the computer, controlling gasanalyzers.

In order to determine the concentration of gaseous components in the studied samples, it is necessary to transform values of gas-analyzer signals, measured in relative units into the value of concentration of the absorbing component in absolute units, for example, in ppm. For this purpose, it is necessary to calibrate gasanalyzers to a gas mixture with the known concentration. To do this, we used the reference gas 
mixture $\mathrm{CO}_{2}-\mathrm{N}_{2}$ (PGS, "PGS service" Ltd, Zarechny town) with a certified content of $\mathrm{CO}_{2}$, equal to $5000 \mathrm{ppm}$ in $\mathrm{N}_{2}$. Plots of the obtained gas-analyzer signals are shown in Fig. 3. Certain difference of derived curves from the $\mathrm{CO}_{2}$ absorption spectrum profile is caused, apparently, by distinct measuring conditions, specifically, an intra-resonator location of the ILPA-1 gas-analyzer detector. This can matter for spectral line parameters study (form, half-width, strength, etc.). For gas-analysis measurements this circumstance can be take into account the detector calibration on utilized laser lines.

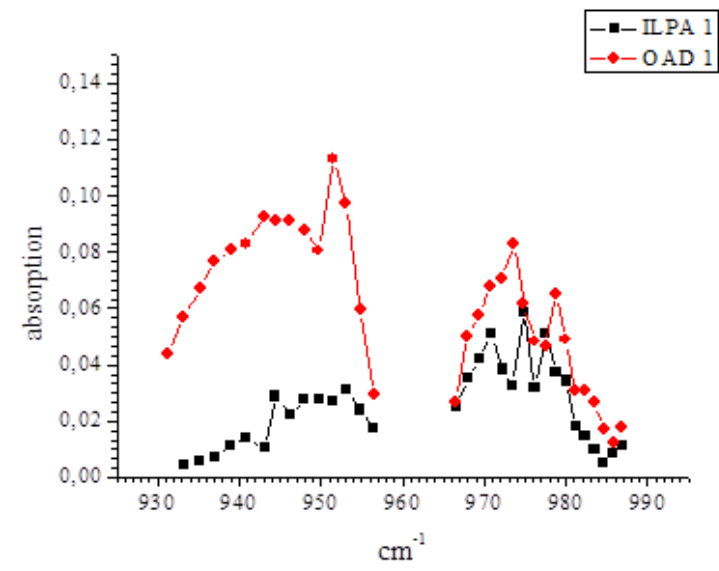

Fig. 3 Spectra of signals of laser optoacoustic gasanalyzers ILPA-1 and OAD-1 when filling in cells with a reference gas mixture of $0.5 \% \mathrm{CO}_{2}$ in $\mathrm{N}_{2}$ at a general pressure of $1 \mathrm{~atm}$ (Y-axis - absorption in arbitrary unit of gas-analysers output signals, $\mathrm{X}$-axis - laser line wavenumber in $\mathrm{cm}^{-1}$ ).

Since the calibration mixture includes only two components, and the nitrogen does not absorb at generation lines of $\mathrm{CO}_{2}$ laser, we can mind that the recorded signal depends only on $\mathrm{CO}_{2}$ absorption. The absorption by the calibrated mixture at $\mathrm{CO}_{2}$ laser lines was calculated in accordance with parameters of spectral lines from the HITRAN database.

\subsection{Description of gaseous samples preparation}

When conducting analytical measurements, the preparation of samples is very important. We also paid a sufficient attention to this problem. Note that measurements of expired air were conducted with the gas-analyzer ILPA-1, while the gas content in the wood annual rings was measured with the gas-analyzer OAD1.

\subsubsection{Preparation of gaseous samples of expired air}

Under standard conditions, there are about 400 volatile compounds in expire air [14]. A part of compounds, for example, $\mathrm{CO}_{2}, \mathrm{~N}_{2}, \mathrm{O}_{2}$, couples of $\mathrm{H}_{2} \mathrm{O}$ reside in the expiration of all peoples in some or other proportion, but the presence or increased concentration of other compounds can testify the fact that a person is ill or under certain stress impact. At the present time, facilities for gathering air, as a rule, make a series of nonstandard devices, produced by researchers themselves. In order to separate a definite gaseous component, the catchers are used, working on one or other principle.

One of the technological problems in gathering samples of expired air is in creating of comfortable conditions for patients, making easy the expiration into the gathering device. In our case, the calibrated gas injector from a serially made spirometer of a volume of 1 liter was used for gathering samples of the expired air. Its nozzle part was changeable in order to escape the risk of infecting.

Air, expired by peoples, is not homogeneous. An adult healthy person expires 0.5 liter of air or more at each breathing cycle. The first $150 \mathrm{ml}$ are expired from the volume of upper breathing tracts, free of the exchange of gases. The informative air samples are to be taken from the pulmonary depth. Therefore, the reserve air volume was used for the gas analysis, expired by a patient into the injector after the corresponding instruction and under the control of medical nurse. Then the input end of the gas-analyzer's probe was put into injector and the mixture was pumped through the detector cell at operation of the gas-analyzer at a chosen radiation wavelength. At reaching the detector signal, maximal for the given value of the letting in, the pumping was cut off, and the wavelength has been scanned throughout the spectrum. At the first stage of investigations on spectroscopic analysis of the expired air by patients we used gas samples without any selection of gaseous components in order to escape any information losses.

The problem of gaseous samples contamination is actual, because there exist admixtures of volatile chemical compounds in any room. These trace compounds were taken into account as the background "noise" in the process of investigations. To increase the reliability of results, we conducted a spectral analysis of room air and air inside the injector immediately before and after series of measurements of expired air.

\subsubsection{Preparation of gaseous samples from wooden annual rings of conifer cuts}

In the analysis, cuts of conifers were used, which were stored from 6 months to several years under laboratory conditions, therefore, the wood of cuts can be thought room-dry. As it follows from the literature, the carbon dioxide is generated by living cells of the wood and stores in the tree stem, because the cambium (a layer of conducting tissues between the bark and wood of the stem) is relatively impermeable for diffusion of gases [15]. In order to develop the method for preparation of samples, we have conducted a testing experiment. An example of the wood ring sample was put into the hermetically sealed exposition chamber with room air under atmospheric pressure. The sample was in the 
chamber during $\sim 6$ months, and then an air sample was taken from the chamber for measuring OA absorption signals. After so long exposition, we failed to fix any difference in the magnitude of OA signals from the sample and air. Therefore, in our following measurements we used the vacuum extraction of gaseous samples from wood rings.

The wood of rings was planed away with special chisels, weighted, and then put in sealed exposition chambers, which were subjected to a short-time evacuation for stimulating the output of the gas, and after 20 minutes measurements began. It was checked that just this time is required for the most intensive emission of gases from wood ring samples. During measurements the gaseous sample from each exposition chamber (at a pressure of $\sim 6$ Torr) was input into sealed OA cell and air was added up to a general pressure of the gaseous mixture of 100 Torr, at which the optimal sensitivity of the detector has been reached. Each series of measurements of values of absorption by analyzed samples was accompanied by measurements of magnitudes of the background absorption by air. The value of difference in absorption by the gaseous sample and by air was informative, it served for determination the relative content of the absorbing component in the sample for each ring with the help of calibrating plot.

\section{Investigation of the carbon dioxide in expired air}

The noninvasive diagnosis of the human organism state through the analysis of the expired air is very attractive, because together with molecules-biomarkers of different illnesses it contains a few percent of $\mathrm{CO}_{2}$, which concentration also attests the state of the human health [16, 17].

The carbon dioxide itself is not a specific marker of certain illness. By data of [18], in expired air of healthy people its concentration is commonly about $4.5 \%$, but higher values, were also observable, which were conditioned by different causes, such as: infecting by the Helicobacter pylori bacteria; the food passing through gastrointestinal tract; dysfunction of the liver, including cirrhosis; excessive growth of bacteria; dysfunction of the pancreas, metabolism of the bile; metabolism of the glucose, etc. In [19] and [20] somewhat less values were obtained: the concentration of the carbon dioxide in expired air of 39 healthy volunteers, aged from 21 to 61 turned out to fall into interval between 1.9 and $4 \%$, at an averaged value of $2.8 \%$; and about $4 \%$ of $\mathrm{CO}_{2}$ was found in the sample of expired air of 16-aged patient-asthmatic. Possibilities of capnometry in the screening of illnesses of respiratory and cardiovascular organs were studied in [17], in which as the critical value of $\mathrm{CO}_{2}$ concentration in the expired air for diagnostics of illnesses was proposed a magnitude of $4.6 \%$, despite the fact, showing that it is impossible to separate these illnesses by the $\mathrm{CO}_{2}$ concentration value.
Below we show measurement results for the carbon dioxide concentration in expired air of healthy persons and patients, suffering from different illnesses. The results were obtained from absorption spectra, recorded with the help of the ILPA-1 gas-analyzer. Since absorption coefficients for $\mathrm{CO}_{2}$ at lines of $\mathrm{CO}_{2}$ laser generation differ less than by two times, the $\mathrm{CO}_{2}$ concentration in samples of expired air was determined by the single-wave method.

In the group of the examined patients with different somatic illnesses from the Tomsk Regional clinical hospital and City hospital no. 3: 11 persons with bronchial asthma and coronary heart ischemia (COI), 12 patients with the community-acquired pneumonia, 17 patients with chronic obstructive pulmonary disease (COPD), 4 patients with ulcer of stomach, and 3 patients with ulcer of duodenum. In the test sampling of expired air participated healthy persons (students of Siberian State Medical University (117 samples)).

Fig. 4 shows an example of the obtained absorption spectra of expired air from range $933-988 \mathrm{~cm}^{-1}$.

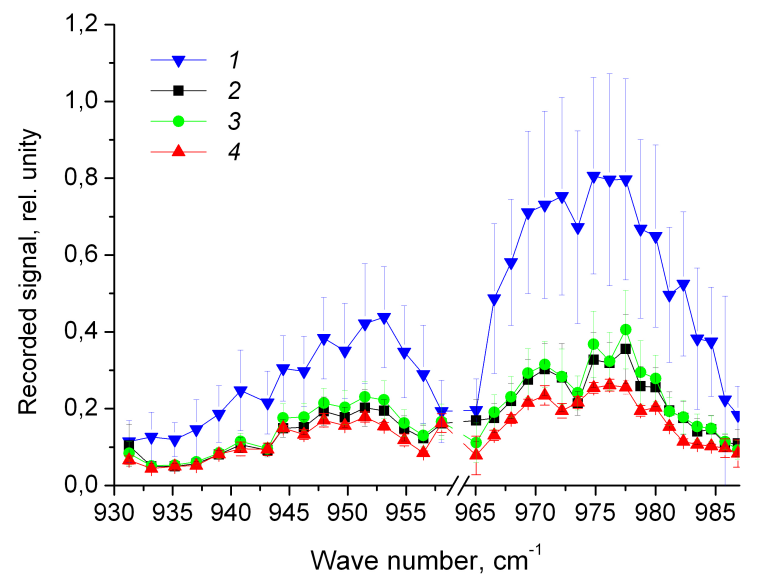

Fig. 4 Absorption spectra of expired air in range $933-988 \mathrm{~cm}^{-1}$ for healthy persons (1) and patients with bronchial asthma (2), COI (3), and duodenal ulcer (4).

Note that for the recorded spectra a wide dispersion is characteristic. Because such dispersion in measurements, made with the reference gaseous mixture, was not observed, we suppose that this dispersion is caused by the variability, characteristic for living objects.

That for range of wave numbers $967-985 \mathrm{~cm}^{-1}$ a greater dispersion of data is characteristic, than for 933-950 $\mathrm{cm}^{-1}$, nonetheless, the $\mathrm{CO}_{2}$ concentration was calculated for signals at each generation line in range 933-988 $\mathrm{cm}^{-1}$ and then the least value was chosen. It was found during the process that a lesser values of $\mathrm{CO}_{2}$ concentration corresponded to the absorption at lines, close to $946 \mathrm{~cm}^{-1}$ for healthy persons and close to $975 \mathrm{~cm}^{-1}$ for patients with differing illnesses. The high values of the $\mathrm{CO}_{2}$ concentration obtained by the magnitude of absorption at other lines can be conditioned by absorption by other gases, residing the expired air. 
Fig. 5 and Table 1 show values of $\mathrm{CO}_{2}$ concentrations in expired air for all groups of examined peoples. Since the obtained values of the $\mathrm{CO}_{2}$ concentration not always corresponded to normal distribution law [11], results are presented in the form of the median Me and 25\%- and 75\%- quartiles $\mathrm{Q}_{1}$ and $\mathrm{Q}_{3}$.

Table 1 Values of $\mathrm{CO}_{2}$ concentration (\%) for all examined groups.

\begin{tabular}{llcccc}
\hline & Examined groups & Size of a group & Me $\left(\mathbf{Q}_{\mathbf{1}} ; \mathbf{Q}_{\mathbf{3}}\right)$ & Min & Max \\
\hline 1 & Healthy peoples & 117 & $5,6(4,6 ; 6,8)$ & 1,9 & 11,1 \\
\hline 2 & Patients with bronchial asthma & 11 & $2,7(2,0 ; 3,3)$ & 1,8 & 3,6 \\
\hline 3 & Patients with COPD & 17 & $3,2(2,4 ; 3,4)$ & 1,0 & 3,9 \\
\hline 4 & $\begin{array}{l}\text { Patients with community- } \\
\text { acquired pneumonia }\end{array}$ & 12 & $2,8(2,2 ; 3,7)$ & 1,1 & 4,6 \\
\hline 5 & $\begin{array}{l}\text { Patients with coronary heart } \\
\text { disease }\end{array}$ & 11 & $3,1(2,4 ; 3,6)$ & 1,9 & 3,9 \\
\hline 6 & Patients with duodenal ulcer & 3 & 2,1 & & 2,0 \\
\hline 7 & Patients with stomach ulcer & 4 & $2,1(2,0 ; 3,1)$ & 1,9 & 3,5 \\
\hline
\end{tabular}

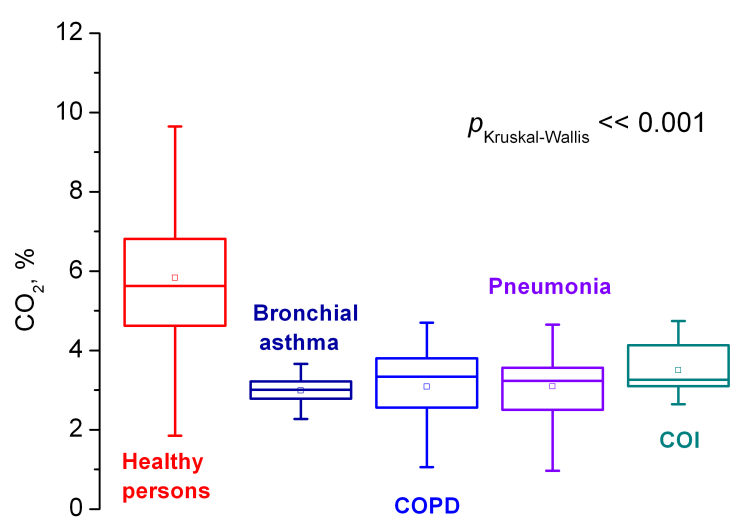

Fig. $5 \mathrm{CO}_{2}$ concentration in expired air of healthy persons and patients with bronchial asthma, COPD, pneumonia, and coronary heart disease.

Obtained values of the $\mathrm{CO}_{2}$ concentration in expired air of healthy peoples are significantly higher, than of patients with different illnesses: the $p$-value by the Kruskal-Wallis test is $p<<0.001$, however, we failed to discern patients by illnesses, using the value of $\mathrm{CO}_{2}$ concentrations. The highest differences are observed, when comparing patients with bronchopulmonary disease and coronary heart disease (51 persons) and patients with ulcer ( 7 persons); by Mann-Whitney test, $p$-value was 0.054 , by the Student's t-test for equal variance assumed, $p=0.053$, and only for equal variance not assumed $p=0.026$, however, the application of the Student's t-test is rightful only for normally distributed data, but in accordance with Shapiro-Wilk normality test in this case it was not so $(p=0.374)$. Significant differences between these two groups of patients can be found only under supposition that $\mathrm{CO}_{2}$ concentrations in expired air of patients with ulcer are lower than of patients with other diseases. In this case, when applying one-tailed Mann-Whitney test, $p=0.028$. However, by data of work [18] the infecting by the bacteria Helicobacter pylori should cause the increase of the $\mathrm{CO}_{2}$ concentration.

On the whole, the obtained values of $\mathrm{CO}_{2}$ concentration in expired air of patient with bronchopulmonary and cardiovascular illnesses is somewhat lower than the corresponding literature data (4.6\% [17] and 4\% [20]), and in expired air of healthy persons they are a few higher $(4.5 \%$ [18] and $1.9-4 \%$ [19]), however, by data from [21] the $\mathrm{CO}_{2}$ concentration strongly depends on the state of the examined persons and conditions, in which they live: a variation of the $\mathrm{CO}_{2}$ concentration, exceeding 1.5 times, was found in expired air of one and the same person, measured in the morning and in the evening. In addition, possibly, the age of persons also is significant for measurements. The age of healthy peoples did not exceed 22 years, and samples from these persons were taken in various time of a day, while ill patients mostly were significantly older, and samples of expired air were taken from them in the first half of a day.

\section{Investigation of gas content in the wood of annual rings of trees}

Forest communities are self-regulating systems and possess of high resistance to varying environmental conditions, however, change drastically of climate can cause irreversible consequences. To forecast such nature-climatic changes, investigations of chronologies of annual tree ring widths are widely used [22, 23]. However, the investigation of solely chronologies of rings' width cannot give a complete notion about the influence of external conditions on the tree growth, therefore, the analysis of the common behavior of widths and gas components of rings is required, which can make deeper the understanding of complex processes, connected with the tree growing.

It is known that $\mathrm{CO}_{2}$ is the basic gaseous component of the stem wood. This gas is formed during respiration of the stem cells and roots [24]. It is also known that a 
certain quantity of water retains in wood stems even after wood drying. We put forward a hypothesis that the residual water of old discs (bound water) can include a part of those $\mathrm{CO}_{2}$, which has been formed when the ring grew, and proposed to use the vacuum method for extracting a gaseous sample, containing $\mathrm{CO}_{2}$ in the wood. To analyze the extracted sample, we used OA gas-analyzer OAD-1 with frequency-retuning $\mathrm{CO}_{2}$ laser.

Applying a specially working out method [25] we have conducted the isotope analysis of the desorbed gas in order to argue that the extracted $\mathrm{CO}_{2}$ is not introduced from the atmosphere. Results have shown that gas samples, desorbed from discs of pine, Siberian stone pine, larch, and spruce are enriched by the light isotope ${ }^{12} \mathrm{C}$ up to values $\left(\delta^{13} \mathrm{C}\right)=-25.3 \%$ for spruce; vary between $-25 \%$ (1894) and $-36.4 \%$ (1986) for Siberian stone pine, between $\delta^{13} \mathrm{C} \approx-25 \%$ and $\delta^{13} \mathrm{C} \approx-30 \%$ for larch, and between $\delta^{13} \mathrm{C} \approx-25 \%$ and $\delta^{13} \mathrm{C} \approx-34 \%$ for pine (Tomsk region, Russia), $\delta^{13} \mathrm{C}=-27 \%$ for Siberian stone pine root and $\delta^{13} \mathrm{C}=-33.5 \%$ for pine root. Evidently, the studied $\mathrm{CO}_{2}$ is produced by stems and roots, but not introduced from the atmosphere, because the isotope composition of the atmospheric $\mathrm{CO}_{2}$ is equal, on the average, to $-8.5 \%$ [26].

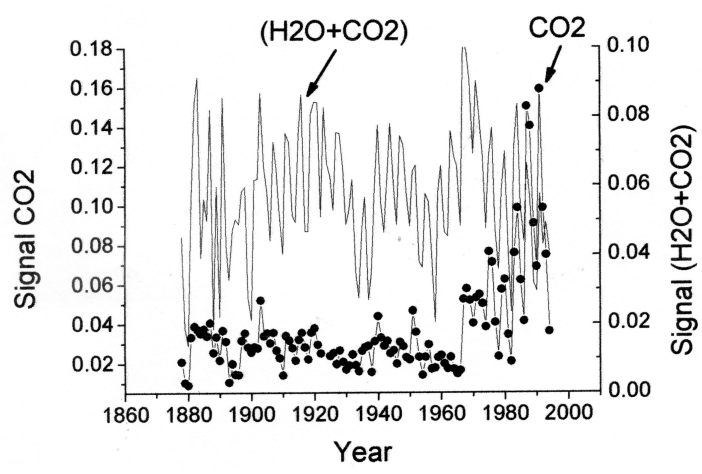

(a)

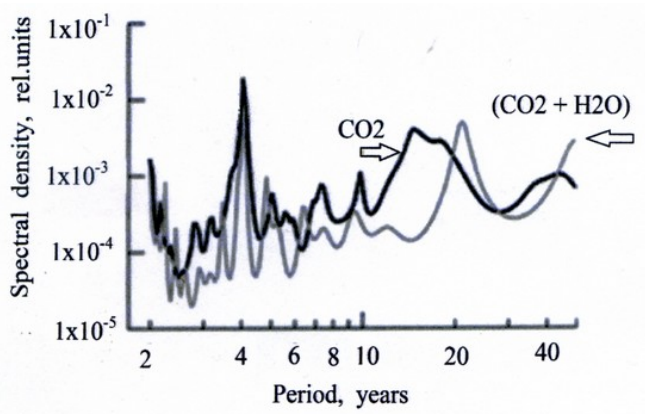

(b)

Fig. 6 The content of $\mathrm{CO}_{2}$ and $\left(\mathrm{CO}_{2}+\mathrm{H}_{2} \mathrm{O}\right)$ in annual rings of the Siberian stone pine (rel. units), depending on the year $(a)$; power spectra of the $\mathrm{CO}_{2}$ and $\mathrm{H}_{2} \mathrm{O}+\mathrm{CO}_{2}$ (at $95 \%$ confidence intervals) $(b)$.

In the result of the experiment we obtained chronologies of $\mathrm{CO}_{2},\left(\mathrm{CO}_{2}+\mathrm{H}_{2} \mathrm{O}\right), \mathrm{H}_{2} \mathrm{O}$, conserved in discs, and pressure variations of gas probes, desorbed from the tree ring wood, the analysis of which allowed revealing a series of characteristics:

1. The obtained chronologies are related with climatic parameters. Investigations of discs of conifer trees (cedar, larch, spruce, pine), grew in the moderate band of West Siberia (Tomsk region), have shown stable fluctuations with the period, close to 4 years, in the obtained chronologies of $\mathrm{CO}_{2},\left(\mathrm{CO}_{2}+\mathrm{H}_{2} \mathrm{O}\right)$ (Fig. 6).

Variations with such a period are found in the nearground temperature, precipitations, and low cloudiness number near Tomsk. The analysis of chronologies of the $\mathrm{CO}_{2}$ and $\mathrm{CO}_{2}+\mathrm{H}_{2} \mathrm{O}$ for the Siberian stone pine (age of about 110 years) points to the possible leading role of precipitations in 4-year fluctuations of the content of gases in the disc. It is possible that there proceeded the synchronization of own quasi-periodical biological processes in the close period with a periodical external impact. Cross-spectral analysis of these chronologies with the index of the solar activity points to their phase synchronization with 11-year solar cycle [27].

2. The emitting of $\mathrm{CO}_{2}$ by large roots and pressure variation in wood rings has a cyclic character. The question on the role of the root system in the $\mathrm{CO}_{2}$ transfer to the tree stem remains controversial up to now [28]. Investigations of discs of large wood roots by the proposed method have shown that the year-by-year variations of $\mathrm{CO}_{2},\left(\mathrm{CO}_{2}+\mathrm{H}_{2} \mathrm{O}\right)$, and total pressure of a gas sample in the wood of root rings are characterized by the cycle, close to 4 years (Fig. 7, 8).

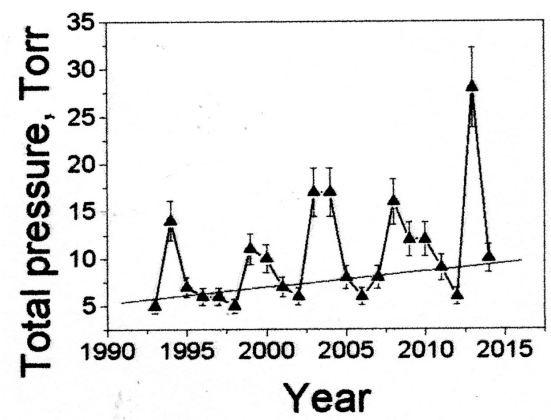

(a)

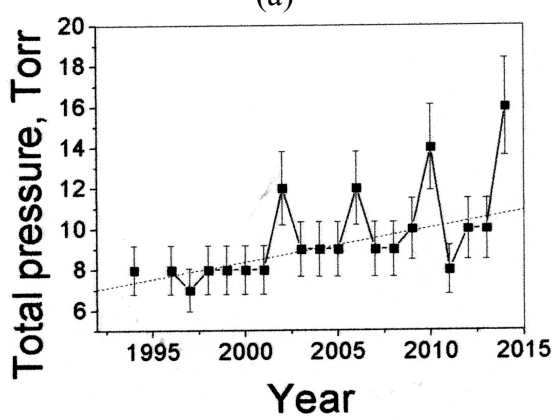

(b)

Fig. 7 Variation of total pressure of gaseous samples, extracted by the vacuum method from wood rings of the pine (a) and Siberian stone pine (b) roots. 


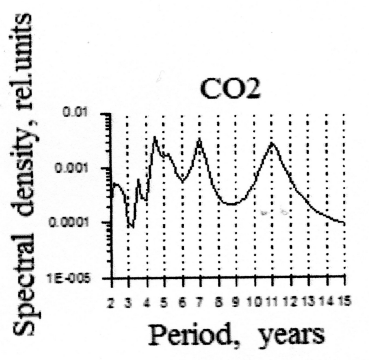

(a)

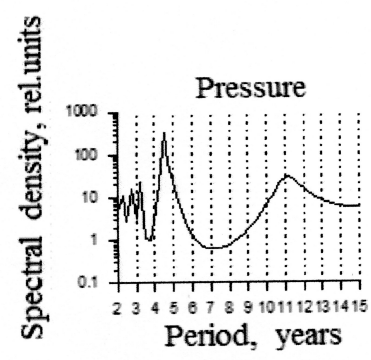

(b)
Fig. 8 Power spectra of variations of the $\mathrm{CO}_{2}$ content (a) and total pressure (b) in the pine root rings.

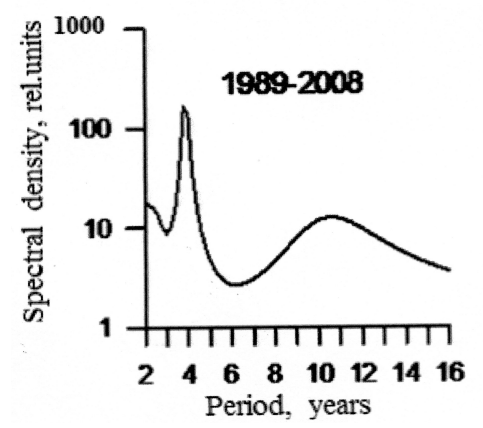

Fig. 9 The result of the spectral analysis of the digitized data from [29] on the global $\mathrm{CO}_{2}$ efflux from the soil to the atmosphere (the trend is removed).

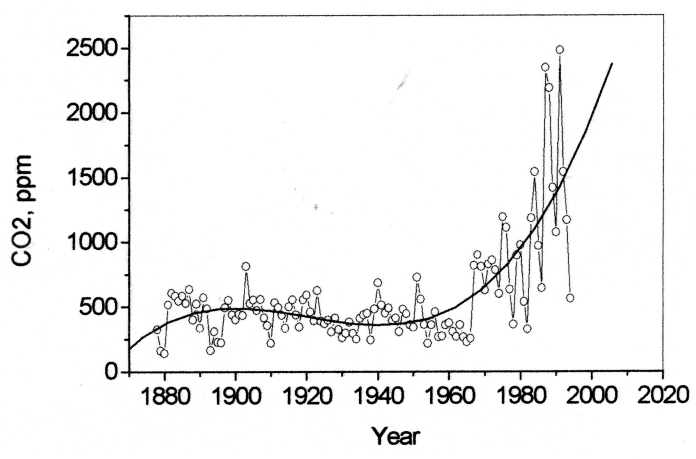

(a)

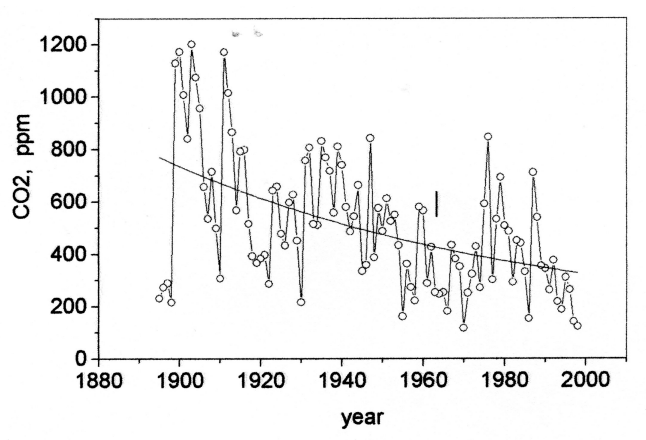

(b)

Fig. 10 The comparison of the year-by-year trends of $\mathrm{CO}_{2}$ content by rings of the Tomsk Siberian stone pine $(a)$ and the Siberian stone pine, grown on the Seminsky Range (b).
The hypothesis was proposed that the $\mathrm{CO}_{2}$ diffuse efflux (root respiration) from large roots into the soil and then in the atmosphere also has a cyclic character. The data processing of the work [29] on the $\mathrm{CO}_{2}$ extraction by the soil from this position has shown that the made proposition is true, because the result of the spectral analysis of digitized data from [29] distinctly discerns the 4-year cycle, which can be related with the root respiration (Fig. 9).

3. $\mathrm{CO}_{2}$ chronologies of trees from different sites are different. The conducted investigations have shown that chronologies of trees, which were grown in different regions, turned to be different. For comparison, present data on the $\mathrm{CO}_{2}$ content in rings of Siberian stone pine discs, grown in the south of the Tomsk region (Fig. 10,a) and on the Seminsky Range (Mountain Altai) (Fig. 10, b). In the first case (Fig. 10, a) the increase of the $\mathrm{CO}_{2}$ content is attributed by us to the variations of atmospheric conditions: the increase of the atmospheric content of $\mathrm{CO}_{2}$ and varying in it ratio of carbon isotopes [10]. In the second case (Fig. 10, b) in mountain conditions, the increased solar radiation and a shorter vegetation period, possibly, influence on the total decrease of $\mathrm{CO}_{2}$ content.

In such a way, it was found that in old discs of conifers 1) the year-to-year distribution of the content of $\mathrm{CO}_{2}$ exists, sorbed by the wood; 2) $\mathrm{CO}_{2}$ concentrations in the wood of rings often exceed the atmospheric one; 3 ) with the increase of tree age the $\mathrm{CO}_{2}$ content in disc rings is observed, correlating with the increase of the atmospheric $\left.\mathrm{CO}_{2} ; 4\right)$ the found variations of the pressure of residual gases in discs point to the fact that the diffuse emission of $\mathrm{CO}_{2}$ by stems and roots into the atmosphere is of cyclic character, therefore, many-year measurements are required for the correct estimate of the forest $\mathrm{CO}_{2}$ emission.

\section{Conclusions}

Investigations of the $\mathrm{CO}_{2}$ content in gas samples of expired air by ill and healthy peoples, as well as $\mathrm{CO}_{2}$ content in gas samples, extracted from wood rings of stems and roots of conifers, were conducted by the method of laser optoacoustic spectroscopy with the use of two types of OA spectrometers-gas analyzers.

The differences in the $\mathrm{CO}_{2}$ concentration in the expirations of examined healthy persons and patients with different illnesses were found: $p$-value by the Kruskal-Wallis test is $p<<0.001$.

The analysis of the yearly content of $\mathrm{CO}_{2}$ has shown that variations of $\mathrm{CO}_{2}$ concentrations are characterized by the cyclicity with a period of 4 years both for woody rings of stems and for rings in large roots, which is related with cyclic characteristics of regional climate.

In the result of investigations, the method of the samples preparation and experimental data analysis was worked out, applicable to a wide range of investigations of gas emissions by biological systems both under stationary (laboratory stand) and mobile (medical institutes) conditions. 


\section{Disclosures}

All authors declare that there is no conflict of interests related to this paper.

\section{Acknowledgements}

This work was made in framework of projects AAAA-A17-117033010037-0 and AAAA-A17$117021310151-7$ of the program of fundamental scientific researches of state academies of sciences for 2013-2020 years.

\section{References}

1. A. B. Antipov, V. A. Kapitanov, Y. N. Ponomarev, and V. A. Sapozhnikova, Photo-Acoustic Technique in Laser Spectroscopy of Molecular Gases, Nauka, Novosibirsk (1984).

2. V. P. Zharov, V. S. Letokhov, Photo-Acoustic Spectroscopy, Nauka, Moscow (1984).

3. B. G. Ageev, Y. N. Ponomarev, and B. A. Tikhomirov, Nonlinear Photo-Acoustic Spectroscopy of Molecular Gases, Nauka, Novosibirsk (1987).

4. V. Zeninari, V. A. Kapitanov, D. Courtois, and Y. N. Ponomarev, "Design and characteristics of differential Helmholtz resonant photoacoustic cell for gas detection," Infrared Physics \& Technology 40(1), 1-23 (1999).

5. V. A. Kapitanov, Y. N. Ponomarev, I. S. Tyryshkin, and A. P. Rostov, "Two-channel opto-acoustic diode laser spectrometer and fine structure of methane absorption spectra in 6070-6180 $\mathrm{cm}^{-1}$ region," Spectrochimica Acta Part A: Molecular and Biomolecular Spectroscopy 66(4-5), 811-818 (2007).

6. V. A. Kapitanov, Y. N. Ponomarev, "High resolution ethylene absorption spectrum between 6035 and $6210 \mathrm{~cm}^{-1}$," Applied Physics B 90(2), 235-241 (2008).

7. S. Bernegger, M. W. Sigrist, "CO-laser photoacoustic spectroscopy of gases and vapours for trace gas analysis," Infrared Physics 30(5), 375-429 (1990).

8. P. L. Meyer, M. W. Sigrist, "Atmospheric pollution monitoring using $\mathrm{CO}_{2}$-laser photoacoustic spectroscopy and other techniques," Review of Scientific Instruments 61(7), 1779-1807 (1990).

9. V. S. Starovoitov, S. A. Trushin, and V. V. Churakov, "Use of lasers on isotope-substituted $\mathrm{CO}_{2}$ molecules in optoacoustic control of atmospheric pollution," Journal of Applied Spectroscopy 59(5-6), 855-859 (1993).

10. B. G. Ageev, Y. N. Ponomarev, and V. A. Sapozhnikova, "Laser photoacoustic method for disc tree-ring gas analysis," World Environment 2(2), 4-10 (2012).

11. B. G. Ageev, O. Y. Nikiforova, "Optoacoustic determination of carbon dioxide concentration in exhaled breath in various human diseases," Journal of Applied Spectroscopy 83(5), 820-825 (2016).

12. I. V. Sherstov, K. V. Bychkov, V. A. Vasiliev, A. I. Karapuzikov, V. V. Spitsin, and S. B. Chernikov, “Twochannel $\mathrm{CO}_{2}$ laser system for heterodyne lidar," Atmospheric and oceanic optics 18(3), 248-253 (2005).

13. A. I. Karapuzikov, I. V. Sherstov, B. G. Ageev, V. A. Kapitanov, and Y. N. Ponomarev, "Laser sensors-gas analyzers based on smart waveguide $\mathrm{CO}_{2}$ lasers and resonance photoacoustic detectors and their applications," Atmospheric and oceanic optics 20(5), 418-423 (2007).

14. M. Phillips, "Breath tests in medicine," Scientific American 267(1), 74-79 (1992).

15. P. J. Kramer, T. T. Kozlowski, Physiology of Woody Plants, Academic Press, New York (1979).

16. V. I. Kuznetsov, S. A. Tarakanov, N. I. Ryzhakov, V. T. Kogan, A. V. Kozlenyuk, and A. A. Rassadina, "Method of highly sensitive non-invasive diagnostics of functional states of organism," Journal of New Medical Technologies 1 (2013).

17. D. V. Lapitski, R. F. Ermolkevich, S. M. Metelski, A. N. Ryapolov, I. A. Manichev, and V. G. Scherbitski, "Capnometry screening ability of ventilatory and circulatory disorders," Military medicine 1(30), 54-57 (2014).

18. S. I. Lukash, "Problems of diagnostics of some diseases on exhaled air," Computer means, networks and systems, 9, 62-71 (2010).

19. K. Stamyr, O. Vaittinen, J. Jaakola, J. Guss, M. Metsälä, G. Johanson, and L. Halonen, "Background levels of hydrogen cyanide in human breath measured by infrared cavity ring down spectroscopy," Biomarkers 14(5), 285291 (2009).

20. J. H. Shorter, D. D. Nelson, J. B. McManus, M. S. Zahniser, S. R. Sama, and D. K. Milton, "Clinical study of multiple breath biomarkers of asthma and COPD $\left(\mathrm{NO}, \mathrm{CO}_{2}, \mathrm{CO}\right.$ and $\left.\mathrm{N}_{2} \mathrm{O}\right)$ by infrared laser spectroscopy," Journal of Breath Research 5(3), 037108 (2011).

21. S. I. Lukash, "Development of the technique of measurement $\mathrm{CO}_{2}$ in exhaled air," Computer means, networks and systems 10, 119-125 (2011).

22. D. V. Tishin, "Dendroclimatological study of Picea $x$ fennica (Reg.) Kom. on the south border of its geographical range," Uchenye Zapiski Kazanskogo Universiteta. Seriya Estestvennye Nauki 150(4), 219-225 (2008).

23. E. A. Vaganov, S. G. Shiyatov, and V. S. Mazepa, Dendroclimatic Study in Ural-Siberian Subarctic, Nauka, Novosibirsk (1996). 
24. R. O. Teskey, A. Saveyn, K. Steppe, and M. A. McGuire, “Origin, fate and significance of $\mathrm{CO}_{2}$ in tree stems," New Phytologist 177, 17-32 (2008).

25. B. Ageev, Y. Ponomarev, V. Sapozhnikova, and D. Savchuk, "A laser photoacoustic analysis of residual $\mathrm{CO}_{2}$ and $\mathrm{H}_{2} \mathrm{O}$ in Larch stems," Biosensors 5(1), 1-12 (2015).

26. M. Rubino, D. M. Etheridge, C. M. Trudinger, C. E. Allison, M. O. Battle, R. L. Langenfelds, L. P. Steele, M. Curran, M. Bender, J. W. C. White, T. M. Jenk, T. Blunier, and R. J. Francey, "A revised 1000 year atmospheric $\delta^{13} \mathrm{C}-\mathrm{CO}_{2}$ record from Law Dome and South Pole, Antarctica," Journal of Geophysical Research: Atmospheres $118(15), 8482-8499(2013)$.

27. V. A. Sapozhnikova, A. N. Gruzdev, B. G. Ageev, Y. N. Ponomarev, and D. A. Savchuk, "Relationship between $\mathrm{CO} 2$ and $\mathrm{H} 2 \mathrm{O}$ variations in tree rings of Siberian stone pine and meteorological parameters," Doklady Earth Sciences 450(2), 652-657 (2013).

28. S. E. Trumbore, A. Angert, N. Kunert, J. Muhr, and J. Q. Chambers, "What's the flux? Unfaveling how $\mathrm{CO}_{2}$ fluxes from trees reflect underlying physiological processes," New Phytologist 197(2), 353-355 (2013).

29. B. Bond-Lamberty, A. Thomson, "Temperature-associated increases in the global soil respiration record," Nature 464(7288), 579-582 (2010). 